\title{
A Matrix Model of a Rangeland Grazing
}

\section{System}

\section{KEITH A. REDETZKE AND GEORGE M. VAN DYNE}

Highlight: A matrix model developed from actual field data from long-term grazing intensity studies was designed to predict grazing systems dynamics. For a given pasture with acreages in several different soil types and a particular stocking rate, the model predicts plant cover and animal production changes in response to variable weather input. The model system is composed of a set of matrix equations, with specific transition matrices for each combination of soil type, grazing intensity, and weather category. Model validation tests were made. Model predictions were compared statistically with data from pastures which were independent replicates of the pastures providing the data used to derive the transition matrices. Model predictions of plant cover dynamics were consistently within the $95 \%$ confidence limits based on field data.

The Great Plains has a semiarid continental climate, subject to large fluctuations in annual precipitation. During wet years the weather may be quite humid and favorable for plant growth,

Authors at the time of the study were with the Natural Resource Ecology Laboratory, Colorado State University, Fort Collins 80523. The senior author is now with the Biology Department, University of Texas, El Paso 79968. Van Dyne is with the College of Forestry and Natural Resources, Colorado State University.

This paper reports on work supported in part by National Science Foundation Grants GB-31862X2 and BMS73-02027 AO2 to the Grassland Biome. U.S. International Biological Program, for "Analysis of Structure, Function, and Utilization of Grassland Ecosystems." Phillip L. Sims is thanked for providing the original data used in developing and testing the model.

Manuscript received September 11, 1975 while in dry years, near desert conditions of low precipitation with high temperature and high evaporation stress may prevail. The vegetation responds to these fluctuations in weather with changes in forage production, ground cover, and species composition; and this in turn affects livestock production. Local soil conditions and the intensity of grazing modify the impact of weather on the vegetation. Because of the economic importance of the livestock industry, this grazing relationship has been widely studied, particularly following the severe and widespread drought of the 1930's. An extensive long-term record of interseasonal changes in grassland vegetation has been accumulated through grazing intensity experiments conducted by state and federal research agencies at various locations in the Great Plains. In these studies pastures were subjected to grazing at light, moderate, and heavy grazing intensities for many years. Information collected generally included animal weights taken monthly and plant cover or biomass at the time of peak biomass or at the end of the growing season for each pasture. In addition, soil type data were taken for the vegetation study plots in several of the studies.

These data collected by many investigators over a long period of years are the basis of an extensive body of knowledge on the interseasonal dynamics of rangeland 
grazing systems. The field records from many of these studies have been acquired and summarized by Redetzke and Paur (1975). These data provide a basis for constructing empirical prediction models. Matrix methods are useful for this type of model development. They provide a means of handling many numbers simultaneously in algebraic manipulations, thereby enabling the incorporation of a large data base into a simulation model with a minimum of mathematical complexity. A basic matrix model was first used in animal population biology by Lewis (1942) and Leslie (1945). Numerous developments since that time have included applications to forest management (Usher, 1966) and timber supply projections (Peden, 1972). Singh and Swartzman (1974) developed a matrix model for describing succession in a tropical grassland, which was based on the percent cover changes calculated from charted quadrats for different grazing intensities over a 3-year period.

The objective of the present paper is to describe the development and testing of a matrix model for a Great Plains grazingland system. The present model uses matrix methods to make predictions of grazing system dynamics. The model is developed from the field records of long-term grazing intensity studies. It simulates changes in plant cover and animal production in response to variation in weather and grazing pressure for different range sites. A subsequent paper will focus on applications.

\section{Model Development}

The general approach to matrix modelling is to express the main properties of the system at a given time in a state vector of discrete categories. A transition matrix composed of the probabilities of changing categories is used to multiply the state vector to derive a new vector from one year to the next. To adapt the matrix approach to a grazing system, a set of discrete categories must be developed for each of the variables involved. We selected the proportional composition of the vegetation cover for our state vector. Cover composition data were available for the specific range sites or soil types and grazing intensities of various previous studies. We used discrete plant cover categories for vegetation-0-5, 5-10, 10-20, $20-50$, and $50-100 \%$ of total ground cover. A separate weather category was assigned for each year on which plant data are available for developing plant response predictions. The years are grouped into dry, normal, and wet categories, and the distribution of precipitation through the year is also included to provide greater resolution (Smith, 1972). The transition matrices were developed by analyzing the data by range site $x$ intensity of grazing $x$ weather category combinations to determine the change in cover categories from year to year.

\section{Vegetation}

\section{Plant Cover}

We represented the vegetation of a range site on a pasture for a particular year by a 5-element state vector of cover categories, composed of the proportions of plots falling into each of these categories on the basis of total plant cover. Change to the succeeding year is accom- plished through multiplying by the transition matrix to give the state vector at the next time step.

In matrix notation the model for changes in plant cover can be written as

$$
\mathbf{v}_{k, l}(t) \mathbf{P}_{k, l, m}=\mathbf{v}_{k, l}(t+l)
$$

Here, the 5-element stage vector $\mathbf{v}_{k, l}(t)$ represents the vegetation cover status of soil type $k$ at time $t$ in years on the pasture grazed at intensity $l$, and each individual vector element $v_{i}$ is the proportion of plots in cover category $i . \mathbf{P}_{k, l, m}$ is a 5 by 5 matrix giving the transitions of cover status for soil type $k$ on the pasture grazed at intensity $l$ during the time period $t$ to $t+1$ (a 1-year interval) having weather of category $m$; each individual matrix element $\mathbf{P}_{i, j}$ is the probability of a plot changing from cover $i$ to cover category $j$ in one time step. The sum of the elements of the $\mathrm{v}_{k, l}(t)$ vector is equal to 1.0 for all values of $l$ and $k$ at all $t$, and the rows of the transition matrices also sum to 1.0 in all cases, making this a stochastic or Markov matrix.

\section{Species Composition}

The species composition of the cover categories of each particular pasture and soil is represented by a matrix giving proportional composition contributed by each species to each of the vegetation cover categories. This matrix, of dimension $5 \times n$, has rows corresponding to the cover categories and columns representing the $n$ species in each of the cover categories. The sum of column elements across species for each of the cover categories is equal to 1.0 .

Yearly changes in composition are made through addition of a transfer matrix composed of species proportion changes anticipated under the particular weather, grazing, and soils conditions. This gives an intermediate matrix in which the columns do not necessarily sum to 1.0. Also, the elements of this matrix could become negative, e.g., as in a drought situation simulation in which cover reductions were imposed repeatedly. This intermediate matrix is normalized or converted to composition by setting any negative elements to zero and dividing the resultant matrix by a vector obtained by summing the rows across species for each cover class of the intermediate matrix.

The model for changes in species composition can be written in matrix notation as

and

$$
\mathbf{S}_{k, l}(t)+\mathbf{C}_{k, l, m}=\mathbf{U}_{k, l}(t+l)
$$

$$
\mathbf{U}_{k, l}(t+l) / \mathbf{u}_{k, l}(t+l)=\mathbf{S}_{k, l}(t+l)
$$

Here, $\mathbf{S}_{k, l}(t)$ is a 5 by $n$ matrix representing the cover composition of soil type $k$ at time $t$, on the pasture grazed at intensity $l$, and each matrix element $s_{i, q}$ is the proportion of cover composition contributed by species $q$ to cover category $i$. $\mathrm{C}_{k, l, m}$ is a 5 by $n$ matrix representing the cover composition changes for soil type $k$ on the pasture which is being grazed at intensity $l$ during the time period $t$ to $t+l$ for weather of category $m$; each matrix element $c_{i, q}$ is the change in cover composition for species $q$ in cover category $i$. $\mathbf{U}_{k, l}(t+l)$ is a 5 by $n$ matrix formed by the sum of the $\mathbf{S}_{k, l}(t)$ and $\mathbf{C}_{k, l, m}$ matrices; and each matrix element $u_{i, q}$ is the sum of $s_{i, q}$ plus the corres- 
ponding $\mathrm{c}_{i, q}$ with negative elements set equal to zero. The $\mathrm{u}_{k, l}(t+l)$ is a 5-element column vector obtained by summing the elements of the $U_{k}(t+1)$ matrix on $i$ across the $n$ species, and each $\mathrm{u}_{i}$ represents the total plant cover in category $i$.

Plant cover by species for each range site type is calculated from the information on the cover composition and proportion of plots in the cover categories. First, the average cover by species for the five cover classes is calculated for each soil. This is done by multiplying the average percent cover of each cover category by the proportion of composition contributed by each species in the cover category. These average percent covers are then multiplied by the proportion of plots in the respective cover categories to give a weighted percent cover. Summing these weighted percents across cover categories by species gives the plant cover by species for each soil type. Average plant cover by species for the pasture is obtained by multiplying the species covers of each soil type by the proportion of the soil type acreage to total pasture acreage and summing across soils.

\section{Application to Grazing Study Data}

In applying the model to a particular data set, the cover category transitions and species composition changes for the transition matrices are calculated directly from the plant data records. The species composition and total cover are calculated and a cover category is assigned to the record. Then the cover category and species compositions from the previous record of the plot are checked, and we increment the cover category transition counter and species composition change sums for the appropriate soil, grazing treatment, and weather conditions under which the plot was observed during that year. The proportion of plots in each of the cover categories, species composition of the cover category arrays, average species cover within the cover categories, weighted species cover within the cover categories, species cover for the particular soil type, and grazing intensity are then calculated. Species composition changes are obtained by comparison with the calculations for the previous year.

\section{Weather}

In classifying weather conditions for each year, an array of monthly moisture deficits is developed as an index of the distribution of growing conditions. Weather records from May of the previous year through September of the particular year are used because a lag effect of weather from the previous growing season has been observed in cover changes for arid and semiarid grasslands (Paulsen and Ares, 1962; Reed and Peterson, 1961). For each month of this 17 -month period the potential evapotranspiration is calculated from temperature and precipitation data according to Thornthwaite (1948).

An index of the overall moisture stress for each year is obtained by summing the monthly moisture deficits. A long-term mean moisture deficit and standard deviation also are calculated for the 17 -month period from available weather data by this method. The weather for each year is then classified as "dry" if its annual moisture deficit exceeded the mean plus the standard deviation, "normal" if within the brackets of the mean plus or minus the standard deviation, or "wet" if less than the mean minus the standard deviation. This procedure is used for classifying weather both from years to be simulated and years used in developing transition matrices.

\section{Animal Production}

For simplicity the prediction of animal production is based only on gain records for each combination of weather condition and stocking rate. We did not consider cover category and species composition of the vegetation when calculating animal production for two reasons. First, animal yields are more closely related to biomass than cover, and since biomass is closely related to weather (Dahl, 1963), including the cover information would have been an unnecessary complication. Second, a very great time span of data would be needed to include all possible combinations of weather and plant cover.

For each weather category and grazing intensity the past grazing records are analyzed for the days grazed, number of animals, initial and final weights, and economic values. Seasonal and daily weight and value gains are calculated. These data are then used as model predictions of production, with the weather condition and stocking rate of the modeled situation determining which values are to be used.

\section{Model Testing}

We tested the model using data from the grazing intensity study conducted on the Eastern Colorado Range Station (Hervey and Dahl, 1959); the basic data we used have been reported by Redetzke and Paur (1975). In this experiment three intensities of steer grazing were applied to six pastures (two sets of three) of native vegetation during summer months. Utilization of available forage by weight averaged near 30,50 , and $70 \%$ for light, moderate, and heavy grazing.

Simultaneous confidence intervals for the observed field data were constructed. We compared model predictions with field data; we used the "Bonferroni $t$ " statistic, which permitted multiple confidence intervals to be used simultaneously with constant $\alpha$ value (Miller, 1966) in these tests. Confidence intervals were calculated first for total plant cover for each year on which there was plant data and then for the three major species-blue grama (Bouteloua gracilis), prairie sandreed (Calamovilfa longifolia), and sand sagebrush (Artemisia filifolia).

\section{Verification}

The procedure outlined above was used in the model development phase to verify that the model could regenerate the data from which it was developed. The transition probability matrices for predicting species composition changes and animal gains were calculated using data from one set of pastures. The model was then run with the initial conditions of these same pastures, using the weather data observed during the study. This verification testing on the dependent data set served as a check on the accuracy of computer programs and methods used to generate the model. Then in validation tests the model was run on the second and independent data set. 
a
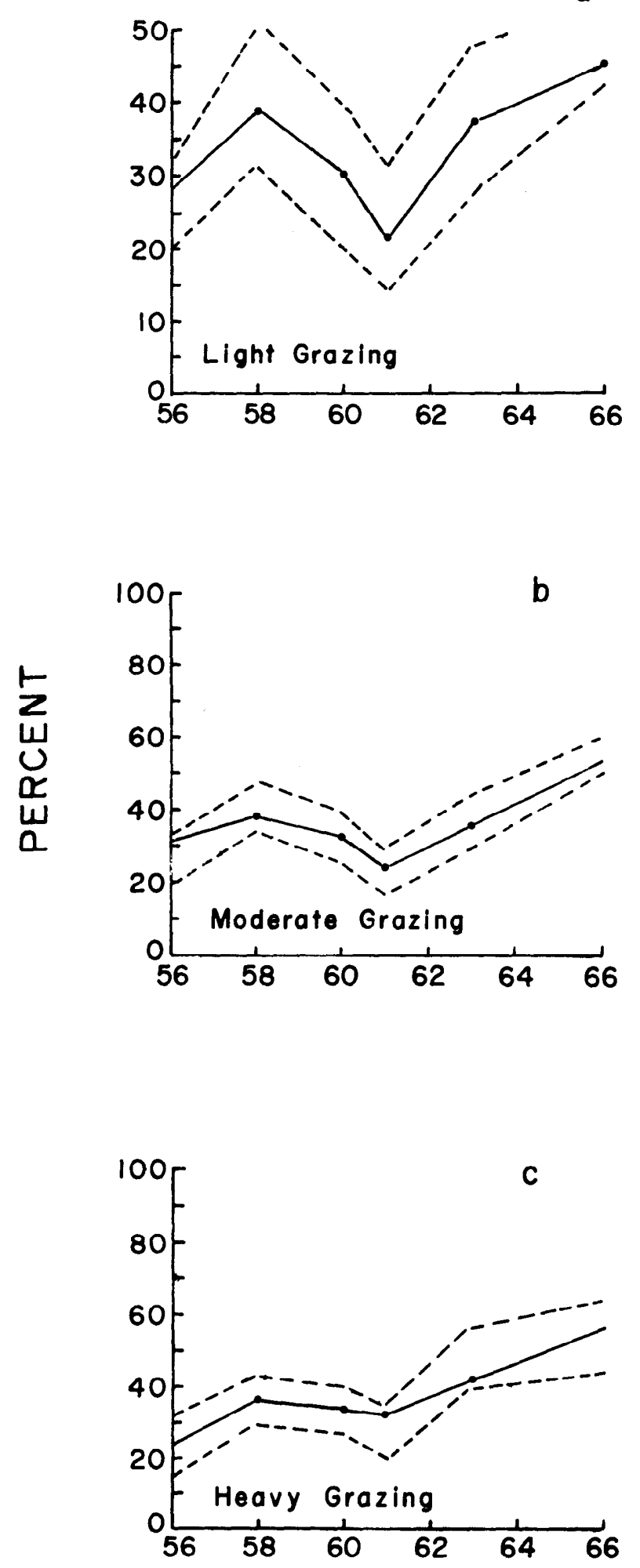
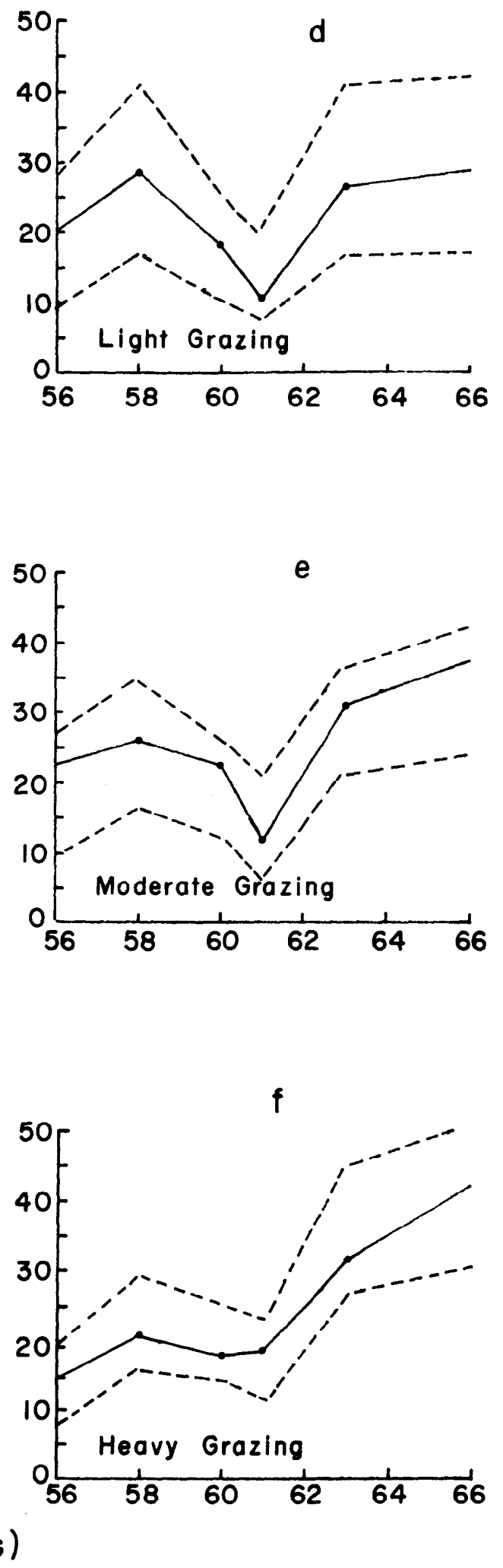

Fig. 1. Graphs of mean cover predicted by the matrix model (solid line) and $\alpha=0.05$ simultaneous confidence limits (dashed lines) calculated from the data for total cover and blue grama from the Akron study on years that data were available. Graphs $a, b$, and c present cover for all plants; in graphs $d, e$, and $f$, blue grama grass cover is presented. 
In the verification tests the predictions of total cover fell within $\alpha=0.05$ simultaneous confidence intervals calculated from the field data for each of these pastures in all of the years. Cover values for the three species contributing the most cover (i.e., blue grama, prairie sandreed, and sand sagebrush) were predicted within the $\alpha=0.05$ simultaneous confidence intervals from the data $98 \%$ of the time. Confidence limits were not calculated for the predicted animal gains because the predicted values were essentially equal to the observed values.

\section{Validation}

The validation testing served to measure the model's accuracy in applications to similar but independent situations outside the specific set of pasture data from which it was developed. The transition matrices in the model were derived from data records from the first set of three pastures. This model then was used to predict vegetation cover changes and animal gains in a second, independent set of pastures. Initial conditions were obtained from the second set of pastures, and the weather record from the experimental period was used to drive the model.

Results from the validation tests (done on the independent set of pastures) indicated that the model also could be relied on to predict information for similar but independent situations. The predictions of total cover fell within the $\alpha=0.05$ simultaneous confidence intervals calculated from the field data for each of these independent pastures.

Cover of blue grama, prairie sandreed, and sand sagebrush was used in validation testing of cover predictions for the independent pastures. Predictions for all three species stayed within the $\alpha=0.05$ simultaneous confidence intervals calculated from the field data on all instances (Fig. 1). Only the confidence limits of observed field data are plotted in Figure 1; the mean values for observed field data would lie midway between the upper and lower confidence limits for all points in time.

The validity of the animal production section of the model was tested on the predictions of average daily weight gain per animal. The predictions of average daily weight gain per animal were within the $\alpha=0.05$ simultaneous confidence intervals for the field data $96 \%$ of the time.

\section{Discussion}

Matrix models of this type are nonmechanistic. The predictions of future events herein are based on probabilities of occurrence rather than on specific system function or biological mechanisms. Since these probabilities are calculated from observation of past events, several things should be noted on plant data requirements of this model. To be realistic the model requires a broad data base. There must be an adequate number of permanent plots per pasture to include the variability in year-toyear changes needed for calculating the probabilities of cover category transition for each soil type. There also must be data from a variety of weather conditions to assure that drought and wet weather a well as normal weather conditions will be represented adequately. In addition, good variability in seasonal distribution of precipitation is also needed. Judging from the data sets examined in this study (see Redetzke and Paur, 1975), those studies with fewer than four plots per soil type for a 10-year span of weather conditions would be inadequate for predicting future plant cover changes.
As with other matrix models, the eigenvalues and eigenvectors of transition matrices can be used to predict the longterm or steady state conditions. To estimate the average steady state for all weather conditions, a set of mean or expected transition matrices can be calculated, using the probabilities of weather categories occurring. There then is only one transition matrix for each soil type of each grazing intensity. By taking the eigenvalues and eigenvectors of this set of matrices, the steady state of vegetation cover for each soil type can be predicted for long-term average weather and applications of light, moderate, and heavy grazing treatments. It also is possible to take the eigenvalues and eigenvectors of the transition matrices for any particular weather situation directly and predict the steady state of the system under that weather situation.

\section{Summary}

A Markov matrix approach was used to model changes in vegetation cover. Weather, soils, grazing pressure, and plant response from long-term grazing studies were handled as discrete variables by developing a set of categories for each. The vegetation of each soil type of a pasture for a particular year was represented by a state vector of total cover categories, showing the proportion of plots in each cover category. The species composition of the cover categories was included in a matrix of species composition, having one column for each species and one row for each cover category of the state vector. The weather category for the year was determined from actual monthly data. Change to the succeeding year was accomplished through multiplying the state vector of cover categories by a transition matrix composed of the probabilities of cover category change and adding a matrix of species composition changes to the composition matrix. Specific cover category transition matrices and species composition change matrices were developed for each combination of soil, weather, and grazing intensity. These were calculated from the plant cover data. The prediction of animal production for the pasture was based on the average daily gain per animal for the particular circumstances of weather and grazing intensity calculated from the data. Eigenvalues and eigenvectors of transition matrices can be used to predict the long-term or steady state vegetation conditions.

Both model verification and validation testing were done using data from a grazing intensity experiment with replicated treatments. These tests were done to determine if the model could generate data comparable to that actually observed in the study. The model was developed using the first set of pastures, and the test runs used the actual weather data, grazing treatments, and soil acreages for the pastures to be simulated. For the model verification tests the simulations were made for the first, dependent data set. For the validation tests the simulations were made for the second, independent set. In the verification and validation tests, the predicted values of total cover species composition and animal production was within $\alpha=0.05$ simultaneous confidence intervals about the actual data means over $95 \%$ of the time. The minimum data requirements for good realism were estimated to be 10 years of weather conditions with at least four plots per soil type.

\section{Literature Cited}

Dahl, B. E. 1963. Soil moisture as a predictive index to forage yield for the sandhill range type. J. Range Manage. 16:128-132. 
Hervey, D. F., and B. E. Dahl. 1959. Intensity of grazing study, p. 1-3. In: Animal nutrition and range management research at the Eastern Colorado Range Station. General Ser. 712. Colorado State Univ. Exp. Sta.., Fort Collins.

Leslie, P. H. 1945. On the use of matrices in certain population mathematics. Biometrika 35:183-212.

Lewis, E. G. 1942. On generation and growth of population. Sankhya 6:93-96.

Miller, R. G. 1966. Simultaneous statistical inference. McGraw-Hill Publ., New York, N.Y. $272 \mathrm{p}$

Paulsen, H. A., Jr., and F. N. Ares. 1962. Grazing values and management of black grama and tobosa grasslands and associated shrub ranges of the Southwest. U.S. Dep. Agr. Tech. Bull. 1270. 56 p.

Peden, L. M. 1972. A Markov model for timber-supply projections. MS Thesis. Colorado State Univ., Fort Collins. 65 p.

Redetzke, K. A., and L. F. Paur. 1975. Long-term grazing intensity data from the Great Plains. US/IBP Grassland Biome Tech. Rep. No. 272. Colorado State Univ., Fort Collins. 120 p.

Reed, M., and R. A. Peterson. 1961. Vegetation, soil, and cattle responses to grazing on northern Great Plains range. U.S. Dep. Agr. Tech. Bull. 1252. $79 \mathrm{p}$.

Singh, J. S., and G. L. Swartzman. 1974. A dynamic programming approach to optimal grazing strategies using a succession model for a tropical grassland. J. Appl. Ecol. 11:537-548.

Smith, F. M. 1972. Growth response of blue grama to thunderstorm rainfall. US/IBP Grassland Biome Tech. Rep. No. 157. Colorado State Univ., Fort Collins. $31 \mathrm{p}$.

Thornthwaite, C. W. 1948. An approach toward a rational classification of climate. Geogr. Rev. 38:55-94.

Usher, M. B. 1966. A matrix approach to the management of renewable resources, with special reference to selection forests. J. Appl. Ecol. 3:355-367. 